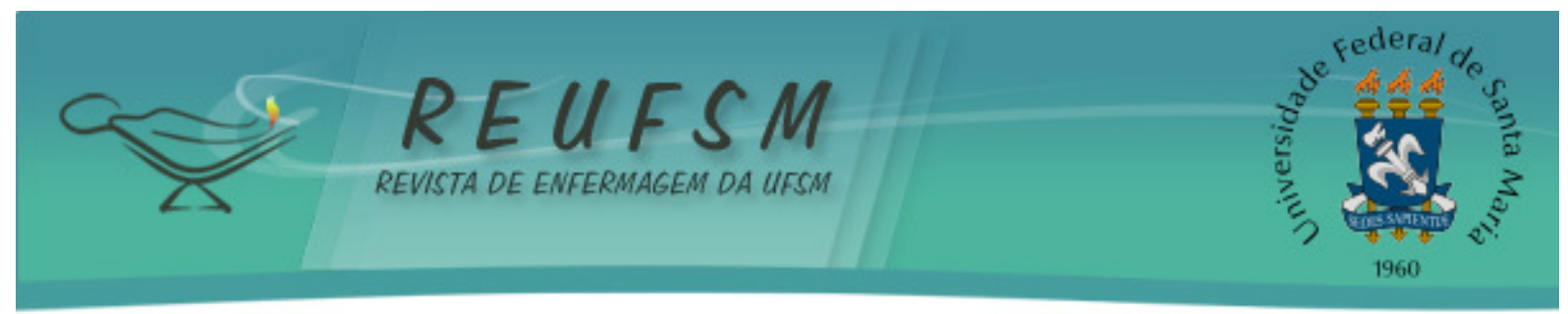

ARTIGO ORIGINAL

\title{
PERCEPÇÃO DO CUIDADO CENTRADO NA FAMÍLIA EM UNIDADE NEONATAL
}

\section{PERCEPTION OF CARE CENTERED ON FAMILY IN THE NEONATAL UNIT PERCEPCIÓN DE LA ATENCIÓN CENTRADA EN LA FAMILIA EN LA UNIDAD NEONATAL}

\author{
Flávia Simphronio Balbino ${ }^{1}$ \\ Gabriela Ferreira Gomes Meschini ${ }^{2}$ \\ Maria Magda Ferreira Gomes Balieiro ${ }^{3}$ \\ Myriam Aparecida Mandetta ${ }^{4}$
}

Doi: $10.5902 / 2179769216340$

RESUMO: Objetivo: estudo com o objetivo de compreender a percepção da família do recém-nascido hospitalizado em unidade neonatal em relação ao cuidado prestado pela equipe de saúde. Método: pesquisa qualitativa, descritiva, que utilizou como referencial teórico os pressupostos do Cuidado Centrado no Paciente e Família. A coleta de dados foi realizada por meio de entrevistas semiestruturadas com sete familiares de recém-nascidos internados em uma unidade neonatal de um hospital universitário em 2011. Resultados: Os dados foram analisados conforme a Análise Qualitativa de Conteúdo, emergindo duas categorias analíticas: satisfação com o cuidado na unidade e dificuldades enfrentadas em relação à equipe e à hospitalização. Conclusão: há uma distância entre a teoria e a prática, sendo o Cuidado Centrado no Paciente e Família um ideal a ser alcançado.

Descritores: Recém-nascido; Família; Enfermagem neonatal.

ABSTRACT: Aim: This study aimed to understand the perception of the family of newborn hospitalised in relation to the care provided by the health team. Method: qualitative descriptive study, which used as theoretical background the Patient and Family Centered Care Model. Data collection was conducted through semi-structured interviews with seven family members of newborns admitted in a neonatal unit of a University Hospital in 2011. Results: The data were analysed according to Qualitative Content Analysis, from which emerged two analytical categories: Satisfaction with the care in the unit and difficulties faced in relation to the staff and the hospitalization. Conclusion: there is a gap between theory and practice, and the Patient and Family Centred Care Model is an ideal to be achieved.

Descriptors: Newborn; Family; Neonatal nursing.

RESUMEN: Objetivo: conocer la percepción de la familia del recién nacido en relación a la atención ofrecida por el equipo de salud. Método: estudio descriptivo cualitativo que utilizó la teoría del Modelo de Cuidado Centrado en el paciente y en la familia. La recolección de datos se realizó por medio de de entrevistas semiestructuradas con siete familias de recién nacidos ingresados en una unidad neonatal de un hospital universitario.

\footnotetext{
1 Enfermeira. Doutora do Departamento de Enfermagem Pediátrica da Escola Paulista de Enfermagem da Universidade Federal de São Paulo. Membro do Núcleo de Estudos da Criança, Adolescente e Família (Necad). São Paulo. SP, Brasil, E-mail: balbinoflavia@hotmail.com

${ }^{2}$ Enfermeira. Universidade Federal de São Paulo. São Paulo. SP, Brasil, E-mail: gabif.gomes@hotmail.com

3 Enfermeira. Doutora do Departamento de Enfermagem Pediátrica da Escola Paulista de Enfermagem, Professora Adjunta da Universidade Federal de São Paulo. Líder do Núcleo de Estudos da Criança, Adolescente e Família (Necad). São Paulo. SP, Brasil, E-mail: mmfgbalieiro@unifesp.br

${ }^{4}$ Enfermeira. Professor Associado do Departamento Enfermagem Pediátrica da Escola Paulista de Enfermagem da Universidade Federal de São Paulo. Líder do Núcleo de Estudos da Criança, Adolescente e Família (Necad). São Paulo. SP, Brasil, E-mail: mpettengill@unifesp.br
} 


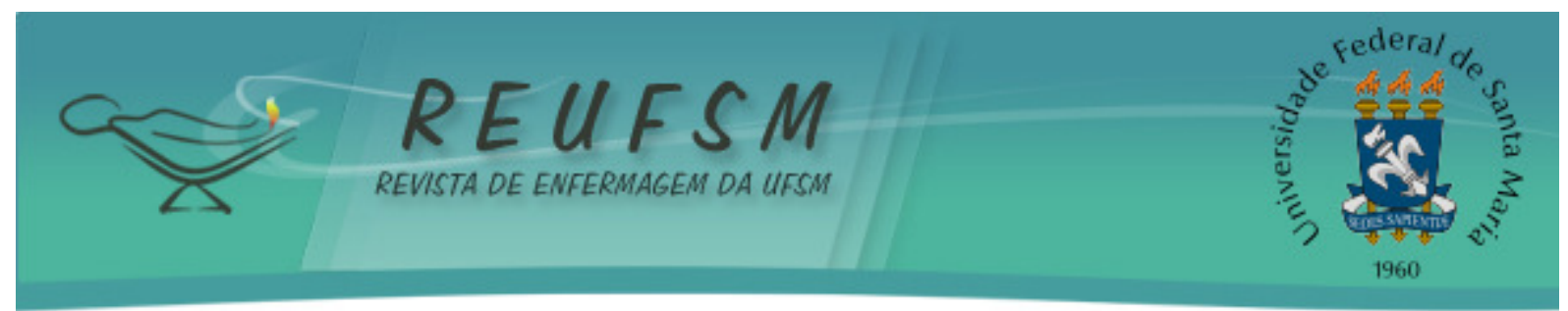

Resultados: datos analizados mediante análisis cualitativa de contenido. Se presentaron dos categorías de análisis: satisfacción con la atención en la unidad y dificultades enfrentadas en relación al equipo y a la hospitalización. Conclusión: hay una brecha entre la teoría y la práctica. La atención centrada en el paciente y la familia es un ideal a ser alcanzado.

Descriptores: Recién nacido; Familia; Enfermería neonatal.

\section{INTRODUÇÃO}

O nascimento de uma criança é um momento de intensa transformação para a família por exigir uma ressignificação dos seus papéis e responsabilidades, além de mudanças em sua estrutura e funcionamento para receber o novo membro. Assim, a família deve aprender a desempenhar novas funções para atender aos desafios que lhe são impostos. ${ }^{1-3}$ No entanto, quando o recém-nascido $(\mathrm{RN})$ apresenta intercorrências de saúde e precisa ser hospitalizado, o sentimento de vulnerabilidade da família é intensificado, em razão do afastamento imposto pela situação, da perda da autonomia nos cuidados da criança e da insegurança e medo que são desencadeados. ${ }^{2}$

Estudos $^{3-5}$ sobre a vivência da mãe com um filho recém-nascido (RN) hospitalizado em unidade neonatal evidenciam que ela se percebe como uma mera visita, teme pela morte do bebê e manifesta sentimentos de culpa que podem inibir seu contato com o filho e interferir na formação do vínculo afetivo. A equipe multiprofissional pode ajudar a família no enfretamento dessa situação com atitude de acolhimento, a fim de lhe proporcionar conforto e segurança, em um ambiente estranho e hostil, em especial quando a família inicia uma nova etapa em seu ciclo de vida. ${ }^{4-5}$

O Cuidado Centrado no Paciente e Família (CCPF) é uma filosofia que reconhece a importância do grupo familiar nos cuidados de saúde de seus membros. ${ }^{6}$ Estudos ${ }^{7-8}$ revelam que pais atendidos nesta perspectiva de cuidado, com o passar do tempo, conseguem fazer perguntas à equipe de saúde e tornarem-se mais confiantes em relação à mesma, o que contribui para minimizar sua ansiedade. Além disso, quando os pais têm acesso irrestrito à internação do filho e podem acompanhar todos os procedimentos conseguem aceitar melhor a condição de saúde do mesmo. ${ }^{9-10}$ Este modelo tem sido cada vez mais enfatizado para promover a participação da família nos cuidados do filho na unidade neonatal. Consiste em ações inclusivas, de forma deliberada, para sua participação no planejamento e prestação de cuidados ao paciente; no desenvolvimento da capacidade dos profissionais para levar em consideração as necessidades de todos familiares e não apenas do paciente; e no reconhecimento da importância das crises interpessoais e do seu impacto na saúde da família, dando ênfase ao estilo colaborativo, o qual respeita suas forças e oferece-lhe apoio para encontrar suas próprias soluções aos problemas identificados. ${ }^{11-13}$

No cotidiano das unidades neonatais é observado que o cuidado está centrado na criança e a família é relegada a uma posição secundária, em um momento difícil e conturbado. Embora os profissionais da equipe de saúde reconheçam que a hospitalização do RN desencadeia uma avalanche de sentimentos e alterações na dinâmica familiar existe uma crença restritiva em relação à presença e participação da família nos cuidados do RN neste ambiente de cuidado. ${ }^{4,7-9}$ Ademais, regras e rotinas, administrativas restringem sua presença, com horários rígidos para a entrada e permanência inclusive dos pais. ${ }^{9-10}$

Questiona-se: como a família do RN percebe o cuidado que the é prestado pela equipe na unidade neonatal? Quais são os elementos que considera relevantes para se sentir fortalecida e o que ela sente quando não é acolhida? Desta maneira, torna-se fundamental dar voz à família do RN hospitalizado, ouvindo-a em suas percepções, a fim de contribuir para o aprimoramento da assistência. Nesse sentido, o objetivo deste estudo 


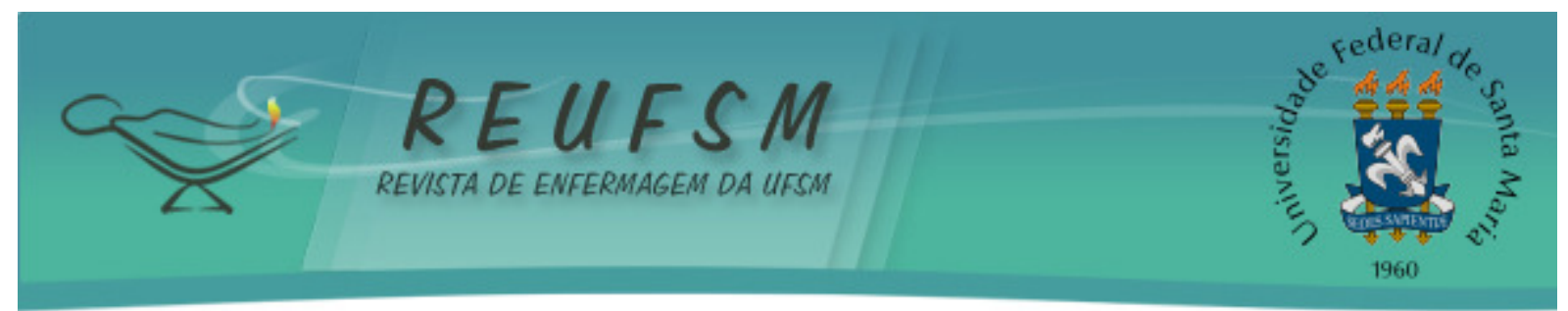

foi compreender a percepção da família do RN hospitalizado em unidade neonatal em relação ao cuidado prestado pela equipe de saúde.

\section{MÉTODO}

Estudo qualitativo, descritivo, realizado em uma unidade neonatal, referência para RN prematuros e com malformações congênitas de um hospital universitário, de nível quaternário, no Município de São Paulo. A unidade está localizada próxima ao alojamento conjunto. Dispõe de uma área física de $90 \mathrm{~m}^{2}$, organizada em oito leitos de terapia intensiva, 14 leitos para cuidados intermediários e uma sala com quatro leitos para o Método Canguru. A equipe multiprofissional é composta de médicos neonatologistas; enfermeiras e técnicas de enfermagem; psicóloga; nutricionista; alunos de pós-graduação latu e stricto sensu das áreas de medicina, enfermagem, fisioterapia, psicologia, serviço social e fonoaudiologia, sob supervisão contínua de docentes de cada área respectivamente. Conta com recursos tecnológicos para atender às necessidades dessa população específica.

Os pressupostos centrais do Cuidado Centrado no Paciente e Família ${ }^{11-12}$ guiaram o olhar dos pesquisadores em direção ao cuidado à família no contexto da unidade neonatal e serviram de base para a condução do processo analítico.

Esse modelo de cuidado está fundamentado em quatro pressupostos centrais relacionados à maneira como os profissionais da equipe de saúde devem se relacionar com a família:

Dignidade e respeito, assegurada quando os profissionais de saúde ouvem e respeitam as escolhas e perspectivas do paciente e da família;

Informação compartilhada que tem por base o processo de comunicação com a família, enfatizando que a equipe deve fornecer informações úteis, com clareza e imparcialidade;

Colaboração, a equipe os pacientes e famílias trabalham juntos no desenvolvimento, implantação e avaliação das políticas e programas institucionais;

Participação, estimulada pela equipe que encoraja e oferece suporte para que os pacientes e famílias participem dos cuidados e das tomadas de decisões.

Participaram do estudo um representante da família de RN. Autores enfatizam que não é necessário incluir todos os familiares na entrevista, podendo haver a participação de um membro apenas, desde que a pergunta norteadora remeta a experiência deles como um todo. ${ }^{14}$

Os critérios de inclusão previamente estabelecidos para participar do estudo exigiam: ser membro da família e ter acompanhado o RN hospitalizado há, no mínimo, 72 horas em cuidados intensivos, intermediários ou em cuidado Canguru; e ter disponibilidade e condições físicas, mentais e emocionais para narrar sua experiência. O critério de exclusão foi ser membro de família de RN fora de possibilidade de cura e/ou em fase de final de vida.

Apos identificação dos participantes elegíveis para o estudo, era feito o convite e esclarecimentos sobre o estudo. Em caso de concordância, assinavam o termo de consentimento livre e esclarecido e agendava-se horário e local privativo para realizar a entrevista semiestruturada, individual, respeitando sua disponibilidade.

No início da entrevista, os participantes eram convidados a contar como estavam vivendo a experiência de ter seu bebê internado na unidade neonatal; a seguir, solicitava-se que relatassem sobre os elementos que os ajudavam no enfrentamento da experiência e aqueles que eram considerados dificultadores. As entrevistas duraram, em média, 20 minutos, foram gravadas em mídia digital e transcritas na íntegra pelos pesquisadores. Para preservar o anonimato, os participantes foram identificados pela letra E, de entrevista, seguida do numeral arábico correspondente à ordem em que foram entrevistados. 


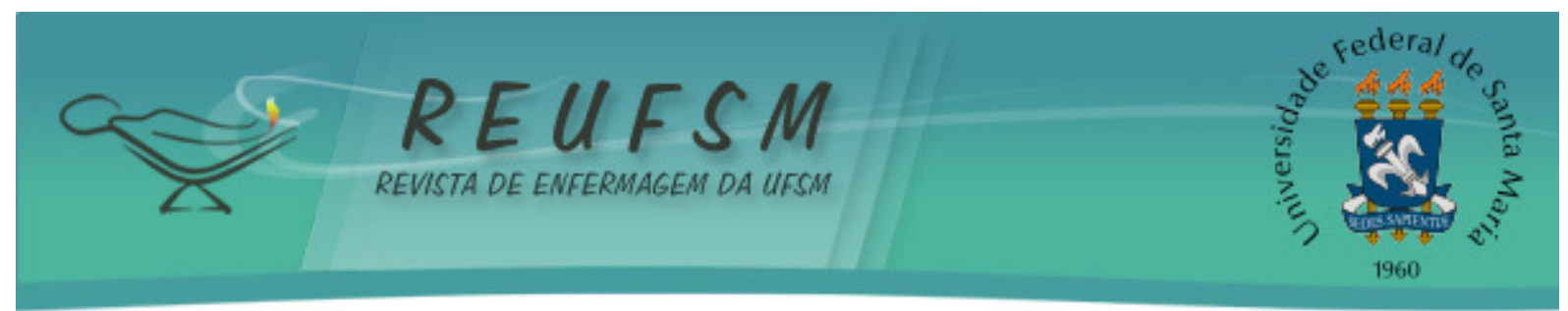

A Análise Qualitativa de Conteúdo guiou o processo analítico. Em um primeiro momento, todas as entrevistas foram lidas na íntegra. A seguir, foram codificadas e agrupadas em subcategorias por similaridades e divergências, sendo ao final, agrupadas em categorias analíticas, conforme a semelhança de significados. ${ }^{15}$

0 desenvolvimento do estudo ocorreu no período de setembro a dezembro de 2011 e atendeu às normas nacionais, Resolução CNS 466/12 e internacionais de ética em pesquisa envolvendo seres humanos. 0 estudo foi aprovado pelo Comitê de Ética e Pesquisa da Instituição, sob o número de protocolo 1359/11.

\section{RESULTADOS}

Participaram do estudo cinco mães, um pai e uma avó materna. 0 tempo médio de permanência do RN na unidade foi de 40 dias.

A análise dos dados permitiu evidenciar que ter um RN com intercorrências de saúde e que necessita permanecer hospitalizado é uma experiência difícil para a família, devido à interrupção de seu sonho de ter um bebê saudável, à termo e que permanece junto da mãe logo após o nascimento. Assim, a experiência é repleta de sofrimento e expectativas, pois a hospitalização gera uma sobrecarga de demandas em todos os membros, impondo-lhes a necessidade de reorganizar sua dinâmica para o enfrentamento dessa nova situação.

A família revela que deseja permanecer com seu ente querido, protegendo-o, com a expectativa de poder levá-lo para casa e retomar o controle sobre sua vida.

No cotidiano das interações com os profissionais, a família observa suas ações, comportamentos e reações em relação ao $\mathrm{RN}$ e a si mesmos, identificando aqueles que considera que cuidam do bebê como gostaria e outros que não o fazem. Tais observações são realizadas de maneira dinâmica durante os encontros e interações que estabelece com eles e conduzem o julgamento da família sobre o cuidado prestado ao RN e a si mesma na unidade neonatal.

As categorias analíticas descritas a seguir compõem a percepção da família em relação ao cuidado prestado pela equipe de saúde:

\section{Satisfação com o cuidado na unidade}

Para a família, a equipe de saúde a ajuda a enfrentar a experiência de modo menos traumático, quando a recebe na unidade de maneira carinhosa e respeitosa desde o início, e conforme vai presenciando a atenção dispensada ao bebê e a si mesma, durante os encontros, para lhe dar informações, ouvi-la em suas dúvidas, e atendê-la em seus questionamentos.

[...] todo o procedimento assim que eu preciso, eu converso com as médicas, com as enfermeiras, elas estão sempre me auxiliando e me atendendo. (E4)

[...] o que me deixou bem mais cuidada foi o fato de segunda feira eu estava na minha casa e a pediatra ligou para a minha casa para falar dele...(E5)

Eu não tenho o que reclamar em relação com a equipe, o que eu preciso elas vêm e me atendem ... não me deixam ir embora com dúvidas. Se eu pergunto, e às vezes até penso que ela esqueceu o que eu perguntei, daqui a pouco ela está vindo, a médica... já me auxilia, conversa comigo...(E1) 


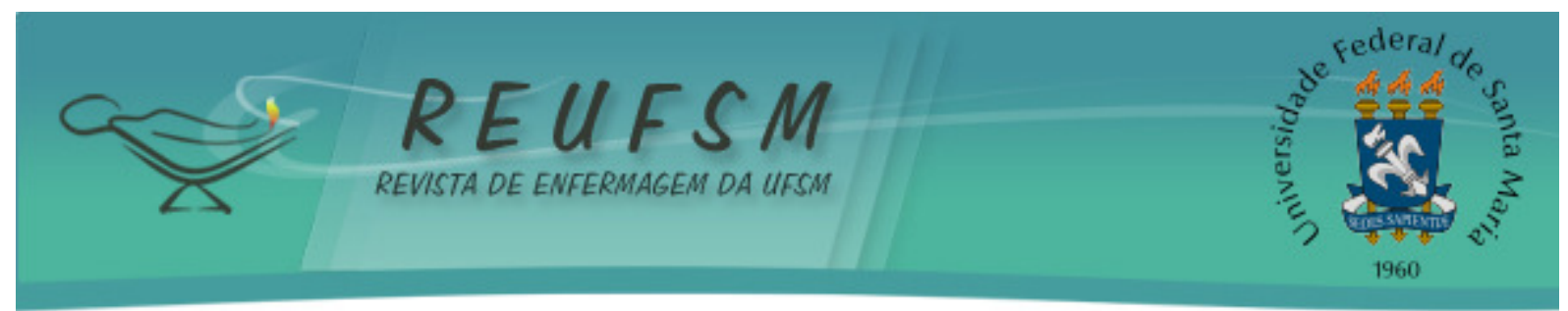

Outro elemento que contribui para o sentimento de satisfação da família com o cuidado é a promoção de sua autonomia. Ao receber orientações da enfermeira e da médica sobre as ações de cuidado com o bebê, a família se percebe fortalecida em sua autoconfiança e cria um espaço, para que aprenda novas maneiras de cuidar.

[...] eu fui embora já esclarecida de tudo, fui embora tranquila! As dúvidas que eu tive, a médica conversou comigo, passou, me acolheu também. (E1)

Eu tinha medo de derrubar, a enfermeira ensinou direitinho, o jeito de não derrubar ele. Eu me senti feliz, segura do que eu estava fazendo, e capaz de fazer em casa depois do que ela me ensinou. (E3)

Como consequência, a família estabelece elo de confiança com a equipe de saúde e atribui a melhora das condições clínicas do bebê à presença constante de uma equipe que cuida de maneira intensa e carinhosa. Isto a faz acreditar que, mesmo em sua ausência, o bebê é atendido prontamente por pessoas amáveis e competentes.

[...] Meu marido sim, ele gostou da equipe. Tanto é que ele falou 'nossa, eu confio, se você precisar ficar em casa, ficar para descansar, pode ficar em casa descansando, pois eles cuidam sempre. (E5)

[...] Eu estou vendo que ele está evoluindo bastante. Então, eu fico muito feliz quando vejo que estão cuidando bem dele.(E4)

Embora seja uma experiência de sofrimento, ao se perceber incluída no cuidado pela equipe, a família tem oportunidade para resgatar suas forças, sentindo-se empoderada para continuar sua luta, na expectativa de poder levar o filho recém-nascido recuperado para casa.

A família revela que ter disponível um canal permanente de comunicação e poder compartilhar informações e dúvidas, tanto com a equipe de saúde como com os demais pais é essencial para se perceber sendo cuidada. A reunião com os pais ajuda a ter suas dúvidas esclarecidas, assim como abertura para questionar algum membro da equipe presente do local, sempre que precisa.

[...] todas as reuniões de terça-feira, sempre quando tem alguma dúvida pode esclarecer, sempre vem uma médica compartilhar as reuniões. (E1)

\section{Dificuldades enfrentadas em relação à equipe e à hospitalização}

A família revela que nem sempre se percebe sendo cuidada pela equipe multiprofissional da unidade neonatal $e$, desta forma, suas necessidades não são plenamente atendidas nesse contexto de sofrimento, sobretudo, quando percebe a falta de acolhimento na unidade; as condições de estrutura física desfavoráveis à sua presença; as dúvidas não esclarecidas pela equipe; a dedicação insuficiente da equipe e a divergência de conduta entre os profissionais. 


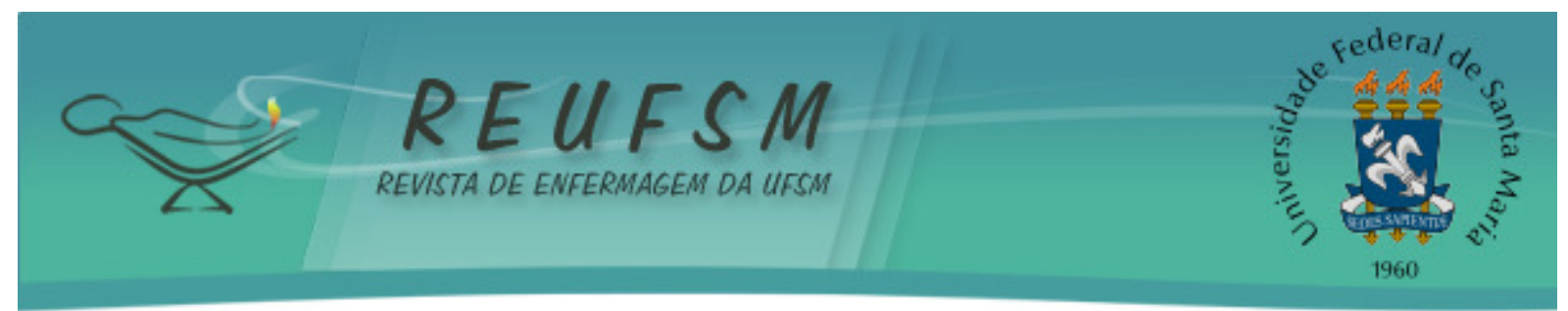

A falta de acolhimento é percebida quando a família tem de aguardar do lado de fora da unidade, em um local inapropriado para se acomodar, até que um membro da equipe a autorize e a conduza até o leito do RN. Aliado a isso, nas visitas subsequentes, a família não conta com nenhum profissional que a acompanhe e a mantenha atualizada em relação à disposição dos leitos e transferências ocorridas. Isto a deixa assustada, sobretudo quando não consegue localizar o RN.

[...] teve uma ocasião que a gente perguntou se podia entrar, e aí falaram que não, que a sala onde nosso bebê estava até então estava em procedimento... ficamos aguardando em pé do lado de fora... aí eu fui de novo e falei, o médico disse que ele mudou de sala... Então a profissional de enfermagem disse: 'ah então está bom, vou ver se pode entrar'. [...] eu tinha falado para ela que o bebê mudou a sala, então ela podia ter falado 'a sala $X$ é aqui, $e$ seu filho está aqui’, não custava uma apresentação. (E2)

A família observa que as condições de estrutura física são desfavoráveis à sua presença, em especial da mãe que se encontra no período puerperal, com dificuldade de permanecer ao lado do RN nas 24 horas, uma vez que não há mobiliário adequado.

[...] Em questão de espaço, deixar uma cadeira mais confortável para a mãe descansar. Eu acho que é necessário, porque tem mãe que fica do começo do dia ao fim da noite com o bebê. (E7)

A falta de informação potencializa a situação de fragilidade da família, especialmente quando se depara com termos técnicos que não compreende, levando-a imaginar que algo de ruim possa estar acontecendo.

[...] quando ela falou, 'ela está com apneia', eu já comecei a chorar, eu falei 'ai meu Deus do céu!', eu já imaginei que era uma coisa, uma doença ruim. (E1)

Além disso, há momentos em que a família percebe divergência de conduta entre os profissionais, desencadeando sentimentos de desconfiança, por imaginar que seu bebê não está sendo cuidado como ela gostaria que fosse.

[...] ele mamou bastante no peito, acho que uns 20 minutos no peito. Aí deram só $10 \mathrm{ml}$, acho que era o que estava prescrito, 10 $\mathrm{ml}$ de leite materno na mamadeira, e queriam dar mais $40 \mathrm{ml}$ na sonda, ele tomou $20 \mathrm{ml}$ e já começou a fazer ânsia, mas mesmo assim a enfermeira queria tentar. (E3)

[...] eu perguntei para a enfermeira: - você colocou a meinha? Mas, outra enfermeira respondeu: eu pus porque o pé dele estava muito gelado! Eu pensei, e agora? Uma enfermeira falou que não estava gelado e a outra falou que estava! e aí? (E4)

A família toma algumas decisões no sentido de se preservar evitando um confronto direto com a equipe, tais como não questionar ou mesmo reclamar de algo que não a satisfaz, ficando na posição de observadora das situações que presencia. 


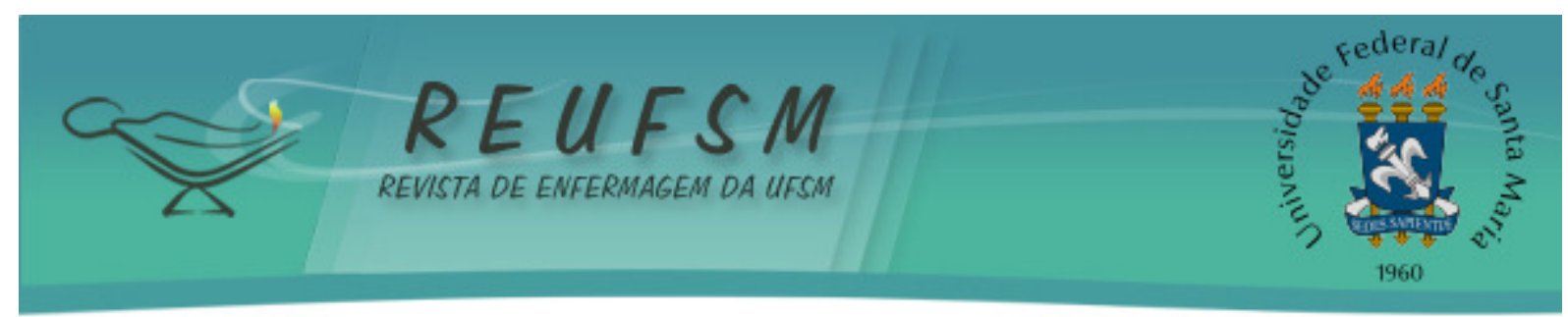

[...] procuro não ficar brigando, ficar discutindo muito, eu fico mais na minha. (E4)

Neste contexto de sofrimento, a família vivencia interações com os profissionais atribuindo-lhes o sentido de cuidado quando é atendida em suas necessidades, respeitada e incluída na assistência prestada ao RN.

\section{DISCUSSÃO}

Ao analisar a experiência da família sob a perspectiva do Cuidado Centrado no Paciente e Família, foi possível perceber que há momentos e situações em que a família se percebe sendo acolhida e com oportunidade para participar dos cuidados do RN, recebendo informações e sendo ouvida, porém há outros em que se percebe desrespeitada em sua capacidade e deixada à parte, sem poder para participar dos cuidados e das tomadas de decisão.

Desta maneira, a análise à luz do Modelo do Cuidado Centrado no Paciente e Família aponta que a abordagem de cuidado realizada pelos profissionais está distante do preconizado por esse modelo, pois o foco ainda é centrado no RN. Isto revela que é preciso avançar para incluir a família como unidade de cuidado, levando em conta suas necessidades. Para modificar essa realidade é preciso sensibilizar e instrumentalizar a equipe, a fim de que ela reconheça a família como unidade que precisa estar fortalecida para poder cuidar desse novo membro.

$\mathrm{Na}$ literatura ${ }^{5,9,16-19}$, os aspectos evidenciados pelas mães de RN internados relacionados ao não atendimento de suas necessidades são inúmeros e fazem eco aos achados neste estudo, tais como: inexistência de uma rotina de informação, falta de acolhimento, uso constante de termos técnicos pelos profissionais, estrutura inadequada para a permanência na unidade e divergência na atuação dos profissionais.

o Cuidado Centrado no Paciente e Família reconhece que a família tem necessidade de ser acolhida e cuidada com respeito e dignidade. Além disso, a família anseia participar da vida do bebê, ainda que não esteja em sua casa, no domínio de sua vida privada, para exercer sua função parental que legitima sua responsabilidade para com seu mais novo membro. ${ }^{13}$

Os participantes, neste estudo, revelam que precisam receber informação que os ajude a compreender a situação, incluindo as condições de saúde do RN e os procedimentos realizados com ele. De acordo com o preconizado pelo Cuidado Centrado no Paciente e Família, a informação compartilhada a ajuda nas tomadas de decisão a respeito do melhor cuidado. ${ }^{5,13}$

Parece que o papel da equipe de saúde é percebido pela família como essencial quando responde aos seus questionamentos e oferece explicações simples sobre as rotinas da unidade neonatal, as condições clínicas e evolução do RN, os tratamentos e equipamentos utilizados. Isto facilita a compreensão sobre a situação difícil que todos da família estão vivenciando.

Estudos apontam que a família se sente satisfeita quando percebe a dedicação da equipe em acolhê-la e ao oferecer-lhe informações sobre seu bebê, sendo esclarecida em suas dúvidas, minimizando seus anseios e medos. ${ }^{5,16,18} \mathrm{~A}$ participação no cuidado desenvolve autoconfiança e segurança para cuidar dele após a alta. ${ }^{16,17}$

Quando suas necessidades são atendidas, esta se sente respeitada pela equipe, pois percebe a abordagem carinhosa, competente e responsável com que ela e o bebê são cuidados. ${ }^{18,20}$ Por outro lado, quando a equipe não considera suas necessidades, deixando-a fora dos cuidados prestados, faz com que se sinta menosprezada e descuidada, criando um espaço para desconfiança e medo, agravando ainda mais o contexto de sofrimento vivenciado. ${ }^{17,19,20}$ 


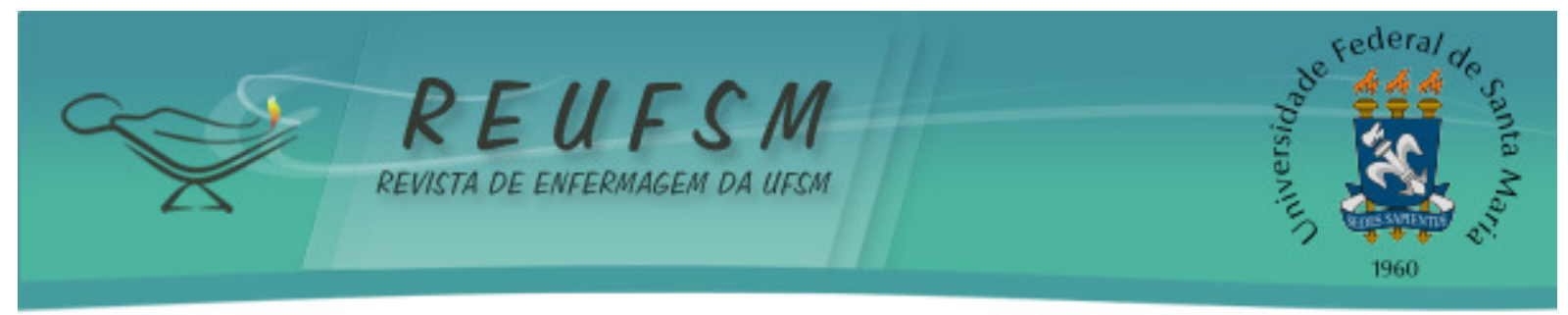

CONCLUSÃO

A análise da percepção da família relativa ao cuidado prestado na unidade neonatal revela aspectos positivos e negativos que devem ser levados em consideração. Os participantes destacaram a receptividade, o carinho e a atenção dispensada, assim como a disponibilidade em ouví-los, oferecendo informações e esclarecendo suas dúvidas, capacitando-os para o cuidado no domicilio como preconiza o modelo do CCPF.

No entanto, as dificuldades apontadas no estudo revelam que este modelo de cuidado ainda está distante de ser alcançado na prática clínica dos profissionais da equipe da referida unidade neonatal, pois não atende a família na maneira como gostaria que fosse atendida.

Recomenda-se avançar na implementação do CCPF no cotidiano da unidade, a partir de mudanças na cultura organizacional por meio de uma estratégia planejada, de discussões e reflexões envolvendo a equipe e gestores; a elaboração de protocolos assistenciais que incluam a família e a sensibilização e capacitação da equipe de saúde para facilitar o acolhimento e o empoderamento da família.

\section{REFERÊNCIAS}

1. Schmidt KT, Sassá AH, Veronez M, Higarashi IH, Marcon SS. A primeira visita ao filho internado na unidade de terapia intensiva neonatal: percepção dos pais. Esc Anna Nery. 2012;16(1):73-81.

2. Coa TF, Pettengill MAM. A experiência de vulnerabilidade da família da criança hospitalizada em Unidade de Cuidados Intensivos Pediátricos. Rev EsC Enferm USP. 2011;45(4):825-32.

3. Merighi MAB, Jesus MCP, Santin KR, Oliveira DM. Cuidar do recém-nascido na presença de seus pais: vivência de enfermeiras em unidade de cuidado intensivo neonatal. Rev Latinoam Enferm [Internet]. 2011 nov-dez [acesso em $2014 \mathrm{dez}$ 22];19(6):[07 telas]. Disponível em: http://www.scielo.br/scielo.php?pid=S0104$11692011000600017 \&$ script=sci_abstract\&tlng=pt.

4. Baylis R, Ewald U, Gradin M, Hedberg Nyqvist K, Rubertsson C, Thernstrom Blomqvist Y. First-time events between parents and preterm infants are affected by the designs and routines of neonatal intensive care units. Acta Paediatr. 2014;103(10):1045-52.

5. Soares LO, Santos RF, Gasparino RC. Necessidades de familiares de pacientes internados em unidade de terapia intensiva neonatal. Texto Contexto Enferm. 2010;19(4):644-50.

6. Gooding JS, Cooper LG, Blaine Al, Franck LS, Howse JL, Berns SD. Family-support and family-centered care in the neonatal intensive care unit: origins, advances, impact. Semin Perinatol. 2011;35(1):20-8.

7. Araújo BBM, Rodrigues BMRD. Vivências e perspectivas maternas na internação do filho prematuro em Unidade de Tratamento Intensivo Neonatal. Rev Esc Enferm USP.2010;44(4):865-72.

8. Molina RCM, Fonseca EL, Waidman MAP, Marcon SS. A percepção da família sobre sua presença em uma Unidade de Terapia Intensiva Pediátrica e Neonatal. Rev Esc Enferm USP. 2009;43(3):630-8.

9. McGrath JM. Strategies for increasing parent participation in the neonatal intensive care unit. J Perinatal Neonatal Nurs. 2011;25(4):305-6. 


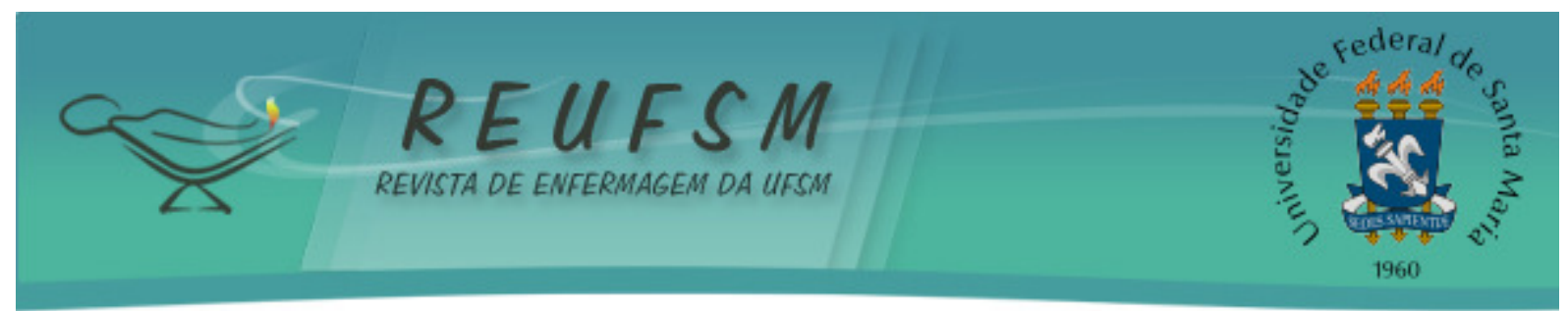

10. Lee LA, Carter M, Stevenson SB, Harrison HA. Improving family-centered care practices in the NICU. Neonatal Netw. 2014;33(3):125-32.

11. Institute for Patient and Family-Centered Care. Advancing Family centered newborn intensive care: a self-assessment inventory [Internet]. 2004 [acesso em $2104 \mathrm{dez} 22$ ]. Disponível em: http://www.ipfcc.org/resources/other/index.html.

12. Pinto JP, Ribeiro CA, Pettengill MM, Balieiro MMFG. Cuidado centrado na família e sua aplicação na enfermagem pediátrica. Rev Bras Enferm. 2010;63(1):132-5.

13. Ramezani S, Shirazi ZH, Sarvestani RS, Moattari M. Family-Centered Care in Neonatal Intensive Care Unit: A Concept Analysis. Int J Community Based Nurs Midwifery. 2014;2(4):268-78.

14. Wright LM, Leahey M. Enfermeiras e famílias: um guia para avaliação e intervenção na família. $5^{a}$ ed. São Paulo: Roca; 2012, 294p.

15. Hsieh HF, Shannon SE. Three approaches to qualitative content analysis. Qualitative Health Research. 2005;15(9):1277-88.

16. Duarte ED, Sena RR, Tavares TS. Práticas cuidadoras que favorecem a integralidade do cuidado ao recém-nascido de alto risco: revisão sistemática. Rev Eletrônica Enferm [Internet] 2010; [acesso em 2014 dez 22];12(3):539-46. Disponível em: http: //www.revistas.ufg.br/index.php/fen/article/view/7509.

17. Roso CC, Costenaro RGS, Rangel RF, Jacobi CS, Mistura C, Silva CT, et al . Vivências de mães sobre a hospitalização do filho prematuro. Rev Enferm UFSM [Internet]. 2014 JanMar [acesso em 2014 dez 22];4(1):47-54. Disponível em: http: / /dx.doi.org/10.5902/2179769210246.

18. Perlin DA, Oliveira SM, Gomes GC. A criança na unidade de terapia intensiva neonatal: impacto da primeira visita da mãe. Rev Gaúcha Enferm [Internet]. 2011 [acesso em 2014 dez 22];32(3):458-64. Disponível em: http://dx.doi.org/10.1590/S198314472011000300004 .

19. Sikorova L, Kucova J. The needs of mothers to newborns hospitalized in intensive care units. Biomed Pap Med Fac Univ Palacky Olomouc Czech Repub. 2012;156(4):330-3.

20. Cockcroft S. How can family centred care be improved to meet the needs of parents with a premature baby in neonatal intensive care? J Neonatal Nurs. 2015;18(3):105-10.

Data de recebimento: $02 / 12 / 2014$

Data de aceite: 04/12/2015

Contato do autor responsável: Flávia Simphronio Balbino

Endereço postal: Rua Napoleão de Barros 754, Vila Clementino, São Paulo - SP, CEP 04024-002

E-mail: balbinoflavia@hotmail.com 